\title{
TWO CASES OF HUMAN INFESTATION BY LARVAE OF LINGUATULA SERRATA
}

\author{
BY \\ W. ST. C. SYMMERS AND K. VALTERIS \\ From the Department of Pathology, University of Birmingham
}

(RECEIVED FOR PUBLICATION APRIL 25, 1950)

Human infestation by Linguatula serrata, one of the family of linguatulids or so-called tongue-worms, is uncommon; the recorded cases appear without exception to have been diagnosed at necropsy, where the parasites were unimportant incidental findings. In an exhaustive survey of the literature we have been unable to find any published record* of a case of infestation by this parasite occurring in the British Isles, and the presence of its larvae in the liver in two patients in Birmingham is therefore of some interest, particularly as the specimen in one case was obtained surgically. Neither patient had ever been out of the country.

\section{The Linguatulids}

The linguatulids are obligate endoparasites belonging to the phylum Arthropoda, within which their precise position seems controversial ; they are usually assigned to the order Acarina in the class Arachnida, of which the most important members are the spiders and mites. Sambon (1922) classified the linguatulids in 13 genera and 43 species. At most five species have been found in man, the only ones occurring with noteworthy frequency as human parasites being Porocephalus armillatus (Armillifer armillatus) and Linguatula serrata (L. rhinaria, L denticulata). $P$. armillatus is found in tropical Africa ; its adult form is a parasite in snakes, in which it inhabits the air-passages and lungs. $L$. serrata has been reported from subtropical and temperate regions, particularly Europe ; the adult parasite lives in the nasal fossae or paranasal sinuses of the dog or, less often, other animals (fox, wolf, horse, goat). The larvae of both species require a mammalian host in which to develop ; infestation in the intermediate host is commonly known as pentastomiasis, the nymph stage of the parasite having formerly been thought to be a distinct species, to which the name Pentastomum was given because the curved claw

\footnotetext{
* [The authors' statement, which they have fully substantiated in a letter to the editorial office, that there are no previously published records of pentastomiasis in this country, deserves further comment since there can be little doubt that such infestation has occurred on a limited scale. The post-mortem records at the London Hospital yield a total of 38 cases in the years 1907 to 1942 inclusive, in which one or more pentastoma cysts were noted in the liver. Most of these were observed before the first world war, the highest incidence being seven cases in 1913. Two only have been recorded since 1927 . The cysts were usually calcified. Microscopic preparations are available of 10 non-calcified examples. In none of these is the preservation of the parasite as good as in the cases described in this paper, though in all other respects the appearances are similar. There is nothing to suggest that their presence excited any clinical symptoms.-EDITOR.]
} 
on each of the four rudimentary limbs surrounding the mouth superficially resembles an oral orifice (Küchenmeister, 1857). The life-cycle of the two species is similar ; the parasites differ significantly only in their definitive hosts and in certain morphological details. Descriptions of these parasites and of their pathogenicity are given by a number of authors (Fischer, 1929 ; Brumpt, 1949), and here only brief mention need be made of some aspects of the biology of $L$. serrata relevant to human infestation by this species, which was first recorded in man by Zenker (1854).

Linguatula serrata. - The adult parasite has a worm-like body, somewhat flattened dorsiventrally and tapering from before backwards; its outline is crenellated by the presence of the approximately 90 rings by which it is characterized. As the vermiform body has some resemblance to a tongue, the parasite acquired the name tongue-worm, by which it is popularly known. The male is white and measures 1.8 to $2 \mathrm{~cm}$. in length and $0.3 \mathrm{~cm}$. in its greatest breadth; the female is greyish, 8 to $10 \mathrm{~cm}$. long and 0.8 to $1 \mathrm{~cm}$. across its widest part. The ova, which contain an embryo when laid, measure 90 by $70 \mu$; they are shed in the nasal secretion of the host, and ingested by the intermediate host on contaminated grass or vegetables eaten raw. The acariform larva hatches in the alimentary tract and by means of its cephalic armature bores through the bowel-wall; it is then carried in the lymphatic or blood stream to the mesenteric lymph-nodes or to the viscera, particularly the liver, lungs, spleen, and kidneys, where it encysts. The larva is said then to undergo about nine moultings during five to six months. The final larva, or nymph (the so-called Pentastomum denticulatum), is 0.5 to $0.6 \mathrm{~cm}$. long and is curved crescent-wise, its ventral surface forming the concavity of the curve ; it has the same number of body-rings as the adult, and each ring has a series of slightly incurved, pointed toothlets near its caudad margin. Further development is dependent upon the parasite reaching the nose of its definitive host ; when ingested the larva may ascend from the stomach to the nose or be carried to the latter in vomitus ejected before it has been killed by the gastric secretion; alternatively, the larva may enter the nose directly while the animal feeds. In the nose maturation is completed. The adult parasite sometimes causes nasal obstruction, but rarely any other disturbance ; occasionally mild, chronic rhinitis develops and causes slight discharge ; the latter or the simple obstruction may lead the animal to rub its muzzle with its paws or against the ground, thus helping in dissemination of the ova. According to Brumpt (1949) the adult parasite has only once been found in man.

Cattle, sheep, and various smaller herbivores, e.g., rabbits, are the usual intermediate hosts of $L$. serrata; the presence of even massive infestation by the larvae appears not to cause any appreciable illness. Rats are sometimes infested and may be the source of infestation in dogs which do not have access to the tissues of the commoner intermediate hosts, e.g., on farms and in butchering establishments.

The incidence of human infestation by the larvae cannot be assessed, as few investigations concerning its occurrence have been recorded; in Berlin, Max Koch (1906) found the larvae in $11.75 \%$ of 400 necropsies, Laengner (1906) in $3 \%$ of 500 necropsies, and Sonobe (1927) in 3.2\% of 500 adult cadavers ; the figures for other parts of Germany and Europe are much lower (Sagredo, 1924 ; Brumpt, 1949). Usually only a single larva is found in each case, and the liver has been the site of 
the majority of the examples recorded. Infestation is said to be particularly rarely found in children (Sonobe, 1927).

\section{Case Reports}

Case 1.-L. P. (United Birmingham Hospitals Reg. No. G.264685), a married woman aged 41, was admitted to the General Hospital, Birmingham, on November 18, 1948. She complained of flatulence and a feeling of fullness after meals, particularly after eating fatty food; these symptoms were of two years' duration. For two months before admission she had been troubled by aching pain in the right hypochondrium, just below the costal margin; the pain occurred after eating and on exertion, and had gradually become more noticeable. Her appetite had become poor, and she suffered from nausea, with vomiting after eating fats. There had been no loss of weight. Apart from these symptoms she was in good health, and worked actively as a district nurse ; her only previous illness was acute appendicitis, a year before the onset of the present symptoms. There was no family-history of illness.

The only clinical abnormality was slight tenderness in the right hypochondrium, in and near the gall-bladder area ; the old appendicectomy scar was healthy.

Investigations.-Radiological examination showed that the gall-bladder, stomach, and duodenum were normal. Bockus's biliary drainage test was negative. The urine was normal. Haematological examination gave the following results: erythrocytes 4.63 million per c.mm. ; haemoglobin $92 \%$ (Haldane), equivalent to $12.7 \mathrm{~g}$. per $100 \mathrm{ml}$. ; leucocytes 5,500 per c.mm., of which neutrophil polymorphonuclears accounted for $66 \%(3,630)$, eosinophils $4.5 \%$ (247), basophils $0.5 \%$ (27), lymphocytes $19.5 \%(1,073)$, and monocytes, $9.5 \%$ (523). Serum chemistry showed: total proteins $7.75 \mathrm{~g}$. per $100 \mathrm{ml}$., albumen 5.8 g., globulin $1.95 \mathrm{~g}$.; bilirubin $0.3 \mathrm{mg}$. per $100 \mathrm{ml}$.; alkaline phosphatase 4 units (King and Armstrong); thymol turbidity test: 3 units (Maclagan); colloidal gold reaction: no precipitate. Hippuric acid excretion: $1.59 \mathrm{~g}$. in one hour following $1.77 \mathrm{~g}$. of sodium benzoate intravenously.

As medical treatment was proving of little value it was decided to perform a laparotomy. At operation (December 6, 1948) a slight inflammatory reaction in the serosa of the gall-bladder and adjacent liver was found, and a small greyish nodule on the surface of the liver in this region was excised ; cholecystectomy was performed.

Progress.-Convalescence was interrupted by repeated pulmonary embolism, which necessitated ligation of the right common iliac vein (January 14, 1949). The patient was discharged to a convalescent home on February 26, 1949, and her general condition slowly improved during the following months; the dyspeptic symptoms gradually lessened, but were still troublesome when she was last seen, in April, 1950.

Following the discovery of a linguatula larva in the liver, the stools and sputum were repeatedly examined for parasites, with negative results. From February to December, 1949, she was treated empirically by courses of neoarsphenamine. A radiograph of her liver in January, 1950, showed no evidence of linguatula nodules ; the lung-fields were clear and the diaphragmatic movements, stomach, and duodenum radiologically normal.

Enquiry at the time when the parasite was found revealed that the patient owned an Alsatian wolf-hound; unfortunately the animal was killed and the carcass destroyed before it could be examined. No signs of nasal disease or of any parasites had ever been observed in it.

Histological Examination.-The excised portion of liver, after fixation in formolsaline solution ( $4 \%$ formaldehyde), measured 8 by $6 \mathrm{~mm}$. on its serosal surface and $4 \mathrm{~mm}$. in depth; an ill-defined grey area, $4 \mathrm{~mm}$. in diameter, could be seen through 
the serosa. The s pecimen was imbedded entire and a representative section cut. When an encysted parasite (Fig. 1) was recognized in the latter the rest of the block was sectioned serially. The parasite was identified as the larva of Linguatula serrata by the ch a r a teris tic circumoral hooks, the closely placed body-rings with their toothlets (Fig. 2) and the internal structure, which was perfectly preserved. The cyst was lined by a very thin, smooth membrane

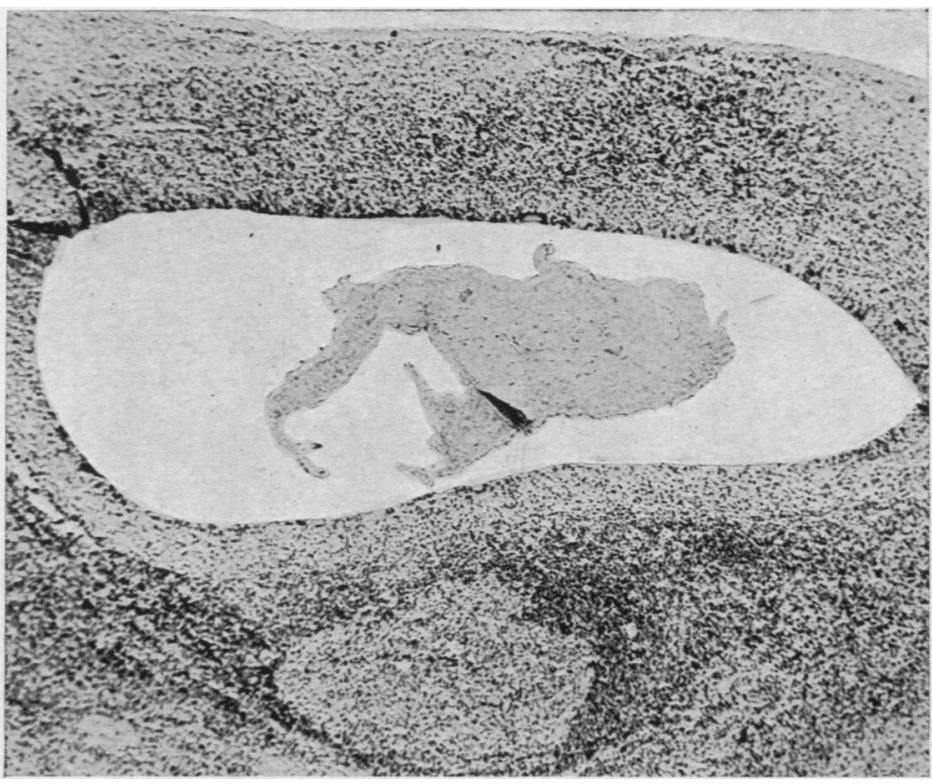

Fig. 1.-Case 1: Encysted larva of Linguatula serrata beneath serosa of liver. (Haematoxylin-eosin, $\times$ 80.)

of homogeneous, refractile, eosinophil material separating its cavity from the host-tissues. The cyst was surrounded by a granulomatous reaction (Fig. 2) ; a narrow zone of

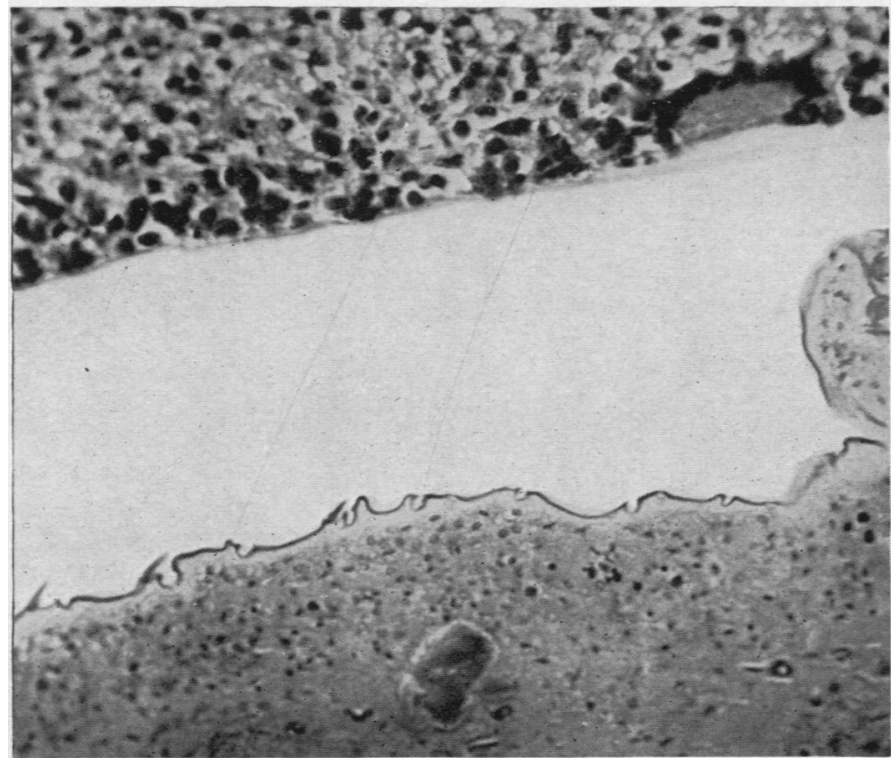

Fig. 2.-Case 1: Granulomatous reaction around encysted larva. (Haematoxylin-eosin, $\times$ 400.) epithelioid histiocytes adjoined the membranous cyst-wall, closely moulded to which were occasional "foreignbody" giant - cells ; many eosinophil leucocytes were present between the epithelioid cells, and a smaller number of lymphocytes. The epithelioidcell zone was surrounded by a considerably wider zone of dense lymphocytic infiltration in which occasional large lymphoid follicles with prominent Flemming centres had formed. There was no fibrosis or necrosis. Serial sections demonstrated the characteristic C-shape of the 


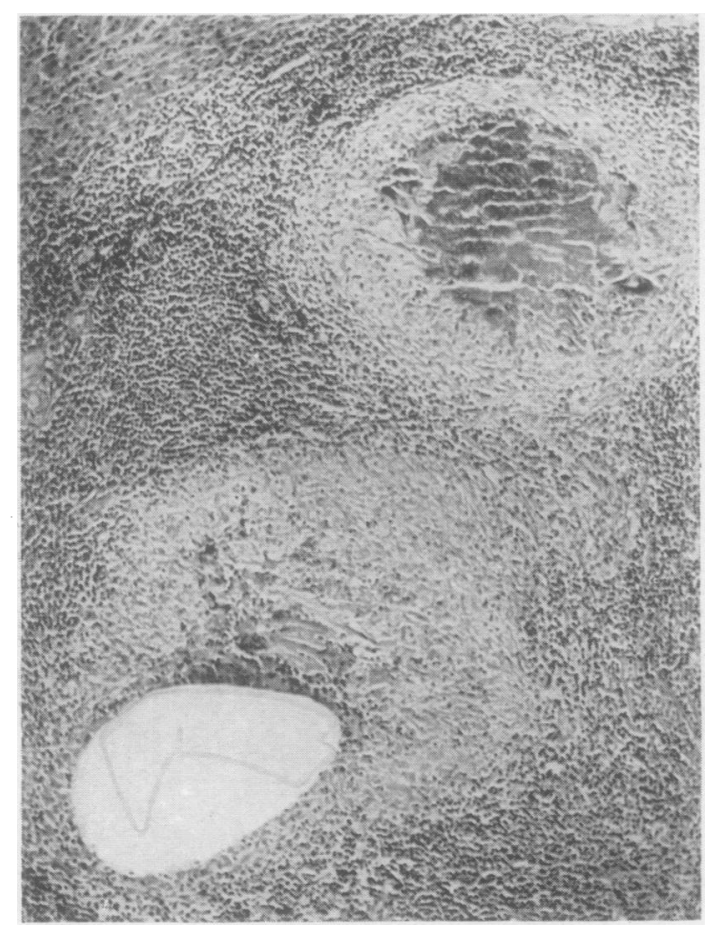

FIG. 3.-Case 1: Pseudotubercle-formation around remnants of cuticle shed by larva during moulting. (Haematoxylin-eosin, $\times$ 96.) larva and the cyst containing it ; in the granulomatous tissue filling the concavity of this curve groups of narrow, homogeneous, refractile, intensely eosinophil structures were present, arranged in palisade fashion and surrounded by macrophages, some of which were multinucleated. In places definite pseudotubercles had formed around these structures, which appeared to be remnants of a cuticle shed by the larva during moulting (Fig. 3).

The hepatic lobules in the vicinity of the granuloma were slightly distorted but otherwise normal. The small portal tracts were heavily infiltrated by lymphocytes, amongst which eosinophil leucocytes were present in considerable numbers. The granuloma reached to the surface of the liver and corresponded with the grey area noted macroscopically; the overlying Glisson's capsule was normal.

Sections of the gall-bladder showed no abnormality.

Case 2.-At necropsy on a girl, aged 17 years, who had died with pulmonary tuberculosis complicated by tuberculous ileitis and tuberculous meningitis, several firm, grey nodules were found scattered throughout the liver, the majority just deep to its capsule. The nodules measured 2 to $3 \mathrm{~mm}$. in diameter, and were thought to be tuberculous lesions undergoing fibrosis under the influence of streptomycin therapy. A portion of liver containing one nodule was fixed in formol-saline solution and paraffin sections examined; unfortunately, serial sections through the whole block were not prepared, contrary to intention, and a considerable part of the lesion was therefore lost.

Histology.-The lesion consisted of two broad rings of practically acellular, partly hyalinized, collagenous fibrous tissue, each surrounding a central mass of amorphous material in which remnants of a parasite were present (Fig. 4). There was little intermingling of the fibrous tissue at the point of contact between the two rings, the angles between which were filled by loose-textured connective tissue, densely infiltrated by lymphocytes. The periphery of the lesion was sharply demarcated from the surrounding liver-tissue, which showed no abnormality. At the surface of the liver the fibrous rings merged into the deep surface of Glisson's capsule, which was not thickened. No eosinophil leucocytes were seen in any part of the tissues.

The parasite was identified as a larva of $L$. serrata by the characteristic ring-markings and toothlets on the cuticle, which was still easily recognizable (Fig. 5). The rest of the larva had partly disintegrated into amorphous detritus and partly become impregnated with calcium salts. It is probable that the two nodules seen in the sections 
represented in fact one lesion; the larva of L. serrata is crescentshaped, and the sections appeared to have been cut through the limbs of the crescent near their ends.

\section{Discussion}

The findings in Case 2 are typical of those described in the majority of previous cases; in most of the latter the parasite had long since died, partially disintegrated and begun to calcify, while the end-result of the reaction of the host's tissues was represented by a dense, fibrous capsule around the remnants of the larva, with little or

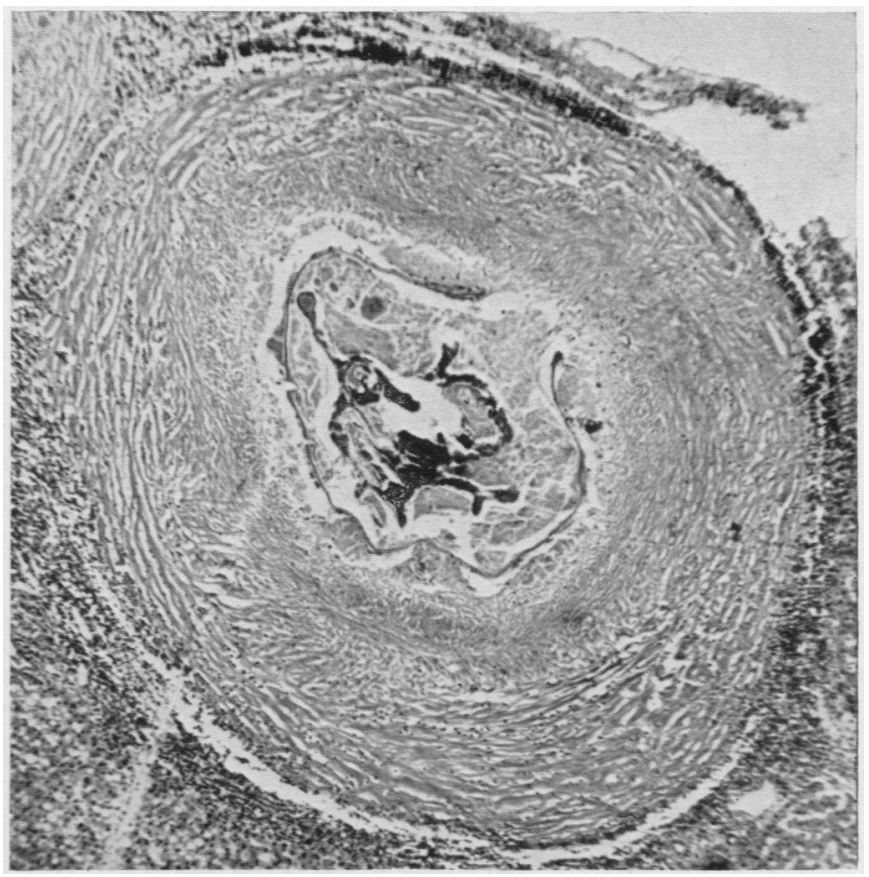

FIG. 4 no remaining sign of active inflammation. In Case 1 , on the other hand, the parasite was perfectly preserved and the granulomatous reaction around the cyst was in an early and active stage, with no demonstrable fibrosis.

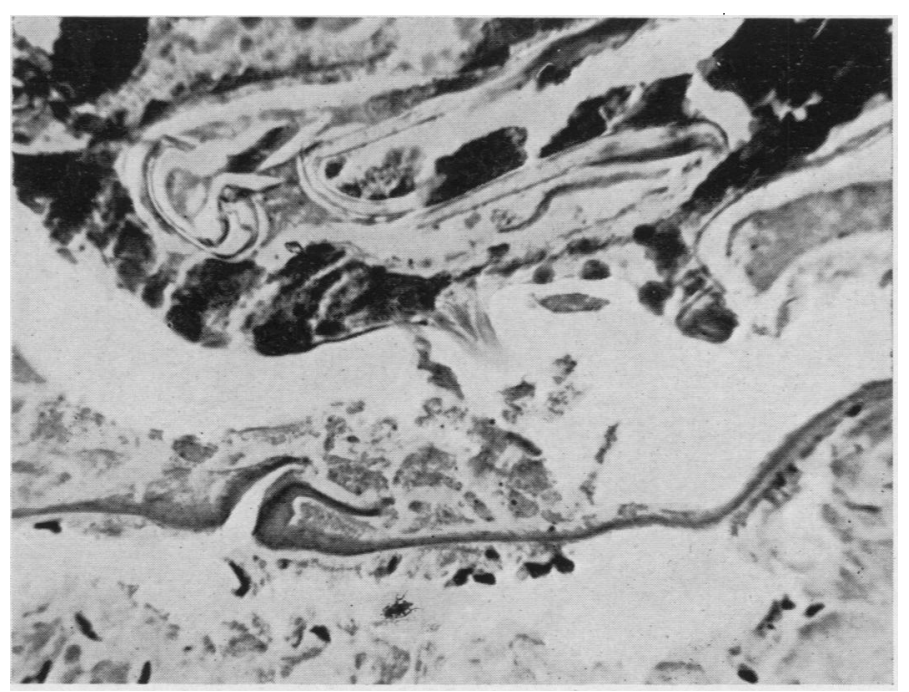

Fig. 5
FIG. 4.-Case 2: " Linguatula nodule" consisting of an outer zone of fibrous tissue surrounding amorphous material in which remnants of the parasite are seen. (Haematoxylin and van Gieson's stain, $\times 74$.)

FIG. 5.-Case 2: Remains of larva, with still recognizable cuticular toothlets. (Haematoxylin and van Gieson's stain, $\times$ 400.) 
Sonobe (1927) described a "nutritive knob or cone" (Ernährungshöcker or -zapfen) formed by the host's connective tissues filling the concavity on the ventral aspect of the encysted parasite, and from which the latter was said to obtain its nutrition. It seems more probable that the larva obtains its nourishment from the fluid in the cyst surrounding it and not by attaching itself to a particular region of the wall of the cyst to suck " nutrient juices" from the host's tissues. The appearances of the granulomatous tissue in contact with the cyst in Case 1 were uniform in all areas, and the membrane lining the cyst was everywhere intact. At the side corresponding with the concave (ventral) aspect of the larva in the same case, compressed remnants of a previously discarded cuticle were found far out towards the periphery of the inflammatory zone around the cyst; these remnants, which had provoked a typical foreign-body reaction, were in the situation described by Koch (1906) as characteristic.

The inflammatory reaction in Case 1 represents an early stage in the process by which the tissues wall off the larva by producing the dense fibrous capsule which is seen in cases of longer duration, and gives the characteristic naked-eye appearance and consistency to the so-called "linguatula nodules." The dead larva ultimately degenerates and the cyst collapses; calcification follows, and the nodules may become visible radiologically (Saupe, 1930). The greatest dimension of the lesion is 3 to $6 \mathrm{~mm}$., rarely more.

Only one case has been reported in which the presence of the larva of $L$. serrata has been suggested as the cause of injury to the tissues of greater extent than the purely local inflammation around the encysted parasite. Sagredo (1924) found a larva in a haemorrhagic lesion in one lung of a youth who had died of encephalitis lethargica ; in addition to haemorrhage there was some destruction and leucocytic infiltration of the lung-tissue, attributed by Sagredo to migration of the larva. Sonobe (1927) gives convincing reasons why the pulmonary lesion in Sagredo's case cannot be accepted as due to the presence of the parasite.

In another case (Roy and Ganguly, 1940) it was suggested that larvae of $L$. serrata, coughed and sneezed up by a woman whose main complaint was of pain over the frontal sinuses, were causally related to the symptoms.

In Case 1 of the present paper it is not possible to go farther than to suggest the possibility that the aggravation of the patient's symptoms and the pain in the right hypochondrium during the two months before her admission to hospital may have been caused by the infestation; how heavy the latter was is unknown. No other evidence of the presence of parasites was found, and attempts to demonstrate calcified linguatula nodules radiologically have so far been unsuccessful.

The source of the infestation remains unknown in each of our cases. No information about the prevalence of linguatuliasis in dogs in Britain is available; the absence of reports on this subject suggests that it is rare.

We have found no reference in medical or veterinary literature to methods of treatment of infestation by these larvae. There is no evidence that the courses of neoarsphenamine given in Case 1 played any part in the slow abatement of the patient's symptoms.

It is of interest to note that infestation by the larva ("Pentastomum constrictum ") of the tropical linguatulid Porocephalus armillatus has on occasion been so heavy 
in man as to cause illness and even death (Cannon, 1942). In contrast with this, there is, up to now, nothing to suggest that infestation by larvae of Linguatula serrata is of any clinical importance. The laborious and time-consuming investigation of necropsy material required to detect cases of the latter would therefore yield results of academic value only. In the course of routine necropsy work in two of the United Birmingham hospitals the opportunity has been taken to search for linguatula nodules in the liver, spleen, kidneys, and mesentery. In 400 consecutive necropsies on adults a positive finding was made only once (Case 2 , above).

\section{Summary}

Two cases of human infestation by the larval form of Linguatula serrata, one of the so-called tongue-worms, are described.

In one patient the infestation, diagnosed by identifying the larva in a portion of liver removed during cholecystectomy, may have played some part in causing her symptoms. In this case treatment with neoarsphenamine was given without conclusive effect. The second case was discovered incidentally at necropsy, and accords with the usually accepted view that Linguatula serrata is not of practical importance in human pathology.

We should like to thank Dr. Ronald St. Johnston for permission to publish the case of his patient (Case 1), and Mr. Fauset Welsh for allowing us to refer to the notes of his findings at operation on this patient.

We are indebted to Mr. Fred Bradley, University of Birmingham, for the photo. micrography, and to Miss S. P. Katt for much assistance.

\section{REFERENCES}

Brumpt, E. (1949). Précis de parasitologie, 6th ed., p. 1060. Paris.

Cannon, D. A. (1942). Ann. trop. Med. Parasit., 36, 160.

Fischer, W. (1929). In Handbuch der speziellen pathologischen Anatomie und Histologie, ed. by Henke, F., and Lubarsch, O. Vol. 4, part 3, p. 703. Berlin.

Koch, M. (1906). Quoted verbatim by Sonobe (1927).

Küchenmeister, F. (1857). On Animal and Vegetable Parasites of the Human Body, trans. by Lankester, E. Vol. 2. London.

Laengner, H. (1906). Z Zbl. Bakt., I. Orig., 40, 368.

Roy, D. N., and Ganguly, S. K. (1940). Indian med. Gaz., 75, 478.

Sagredo, N. (1924). Virchows Arch., 251, 608.

Sambon, L. W. (1922). J. trop. Med. Hyg., 25, 188, 389.

Saupe, E. (1930). Röntgenpraxis, 2, 401.

Sonobe, K. (1927). Virchows Arch., 263, 753.

Zenker, F. A. (1854). Z. rat. Med., 5, 212. 